\title{
Additivity of values for phosphorus digestibility in corn, soybean meal, and canola meal in diets fed to growing pigs
}

\author{
Yue She ${ }^{1,2, a}$, Qiuyun Wang ${ }^{1, a}$, Hans H. Stein ${ }^{3}$, Ling Liu ${ }^{1}$, Defa Li ${ }^{1}$, and Shuai Zhang ${ }^{1, *}$
}

\author{
* Corresponding Author: Shuai Zhang \\ Tel: +86-10-6273-1109, Fax: +86-10-6273-3688, \\ E-mail: zhangshuai16@cau.edu.cn \\ ${ }^{1}$ Ministry of Agriculture Feed Industry Centre, State \\ Key Laboratory of Animal Nutrition, China Agricultural \\ University, Beijing 100193, China \\ ${ }^{2}$ Key Laboratory for Feed Biotechnology of the Ministry \\ of Agriculture, Feed Research Institute, Chinese \\ Academy of Agricultural Sciences, Beijing 100081, \\ China \\ ${ }^{3}$ Department of Animal Sciences, University of Illinois, \\ Urbana, IL 61801, USA \\ a Yue She and Qiuyun Wang have contributed equally \\ to this study. \\ ORCID \\ Shuai Zhang \\ https://orcid.org/0000-0001-5435-2640
}

Submitted Jul 23, 2017; Revised Sept 30, 2017; Accepted Jan 18, 2018
Objective: This study was conducted to determine the apparent and standardized total tract digestibility (ATTD and STTD) of phosphorus (P) in corn, soybean meal (SBM), and canola meal (CM), and additivity of values for ATTD and STTD of P in corn, SBM, and CM in diets fed to growing pigs.

Methods: Thirty-six growing barrows (initial body weight of $21.6 \pm 1.7 \mathrm{~kg}$ ) were placed in metabolism crates and allotted to a completely randomized design with 6 diets and 6 pigs per diet. Six diets were formulated using corn, SBM or CM as the sole source of $\mathrm{P}$, or corn and SBM, or corn and CM, or corn, SBM, and CM as the P source in each diet, respectively. Fecal samples were collected for $5 \mathrm{~d}$ following a $7 \mathrm{~d}$ adaptation period to the diets.

Results: Values for ATTD and STTD of P in corn, SBM, and CM in growing pigs were $33.12 \%$ and $37.76 \%, 50.19 \%$ and $56.62 \%, 34.93 \%$ and $39.45 \%$, respectively. The ATTD and STTD of P in SBM were greater $(\mathrm{p}<0.05)$ than those in corn and CM. However, there were no differences in the ATTD or STTD of P between corn and CM. The determined STTD of $\mathrm{P}$ in the mixture of corn and SBM, corn and CM, and corn, SBM, and CM is not different from the calculated STTD values.

Conclusion: Values for STTD of P in corn, SBM, and CM are additive in their mixture fed to growing pigs.

Keywords: Additivity; Apparent Total Tract Digestibility; Standardized Total Tract Digestibility; Phosphorus; Growing Pigs

\section{INTRODUCTION}

Formulating swine diets precisely based on available phosphorus (AP) can not only reduce the cost of feed but also alleviate environmental phosphorus $(\mathrm{P})$ pollution resulting from pig production [1,2]. Traditionally, apparent total tract digestibility (ATTD) of $\mathrm{P}$ was used to evaluate the AP in feed ingredients for pigs [3]. However, it has been demonstrated that ATTD values for $P$ are influenced by endogenous P losses (EPL) [4-6], but basal EPL of pigs can be determined using a P-free diet [7]. If ATTD is corrected based on basal EPL, values for standardized total tract digestibility (STTD) of P will be calculated [4]. These values are not influenced by EPL, and are therefore, believed to be additive in mixed diets [4]. However, no literature was published to verify this hypothesis on pigs.

Corn and soybean meal (SBM) are the most common feed ingredients used to formulate swine diets. But canola meal (CM) is increasingly used in diets for pigs as well $[8,9]$. Values for STTD of P in corn, SBM, and CM by pigs have been determined in several studies [10-14], but it is not known if these values are additive in mixed diets.

The present experiment was conducted to test the hypothesis that values for the ATTD and STTD of P in pigs are different among corn, SBM, and CM, and values for STTD of $\mathrm{P}$ in mixed diets are additive. Therefore, the objectives of this study were to determine the 
STTD of P in corn, SBM, and CM on growing pigs, and to evaluate the additivity of STTD values obtained in these ingredients in mixed diets when fed to growing pigs.

\section{MATERIALS AND METHODS}

The protocol for this experiment was reviewed and approved by the Ethics Committee on the Use and Care of Animals, China Agricultural University (Beijing, China). The experiment was conducted at the Swine Nutrition Research Centre of the National Feed Engineering Technology Research Center (Chengde, Hebei Province, China).

\section{Animals, diets, feeding, and sample collection}

Thirty-six barrows (Duroc $\times$ Landrace $\times$ Yorkshire) with an initial body weight (BW) of approximate $21.6 \pm 1.7 \mathrm{~kg}$ were selected. Before the start of the experiments, pigs were placed in stainless steel metabolism crates $(1.4 \mathrm{~m} \times 0.45 \mathrm{~m} \times 0.6 \mathrm{~m})$ for $1 \mathrm{wk}$. During the pre-experimental period, pigs were fed a nutritionally balanced commercial diet (crude protein [CP], $18 \%)$ which meets or exceeds the requirements for all nutrients [4].

A total of 6 diets were formulated. Three diets were formulated using corn, SBM or CM (Table 1) as the sole source of $\mathrm{P}$ in each diet, respectively. Three additional diets were formulated using corn and SBM, or corn and CM, or corn, $\mathrm{SBM}$, and CM as the P source in each diet, respectively (Table 2). The experiment lasted 19 days, including 7 days for cages adaptation, 7 days for diets adaptation and the last 5 days for feces collection. The ATTD and STTD of P for each diet were determined using total collection method. Diets were provided a daily amount of feed equivalent to $4 \%$ of BW measured at the initiation of the adaptation period, and were divided equally into 2 feedings provided at 08:00 and 16:00. Samples of diets were collected for chemical analysis. During the experiment, all pigs had free access to water from a
Table 1. Analyzed chemical composition of experimental ingredients (\%, unless otherwise indicated; as-fed basis)

\begin{tabular}{lccc}
\hline Item & Corn & SBM & CM \\
\hline GE $(\mathrm{kcal} / \mathrm{kg})$ & 3,764 & 4,183 & 4,180 \\
$\mathrm{DM}$ & 88.30 & 88.59 & 88.87 \\
$\mathrm{CP}(\mathrm{N} \times 6.25)$ & 6.45 & 47.79 & 34.19 \\
$\mathrm{NDF}$ & 4.43 & 10.05 & 30.89 \\
$\mathrm{ADF}$ & 3.74 & 8.19 & 18.78 \\
Ash & 1.31 & 6.33 & 6.67 \\
$\mathrm{Ca}$ & 0.03 & 0.51 & 0.76 \\
$\mathrm{P}$ & 0.34 & 0.70 & 1.10 \\
Phytate & 0.63 & 1.60 & 3.12 \\
Phytate-bound $\mathrm{P}^{1)}$ & 0.18 & 0.45 & 0.88 \\
Phytate-bound P (\% of total P) & 52.94 & 64.28 & 80.00 \\
Nonphytate-bound $\mathrm{P}^{2)}$ & 0.16 & 0.25 & 0.22 \\
Nonphytate-bound P (\% of total P) & 47.06 & 35.71 & 20.00 \\
\hline
\end{tabular}

SBM, soybean meal; $C M$, canola meal; GE, gross energy; DM, dry matter; $C P$, crude protein; NDF, neutral detergent fiber; $A D F$, acid detergent fiber.

1) Phytate-bound P was calculated as $28.2 \%$ of phytate [18].

${ }^{2)}$ Nonphytate-bound $P$ was calculated as the difference between total $P$ and phytate-bound P.

low-pressure drinking nipple. The 5-d total fecal collection was accomplished according to the procedures described by Song et al [15]. Fecal collection started at 16:00 on day 14 (the last day for diet adaptation) immediately when feces appeared in metabolism crates, and terminated at 16:00 on day 19. Feces were collected three times per day at 8:00, 16:00 and 22:00, and all feces were placed in plastic bags and stored at $-20^{\circ} \mathrm{C}$. At the end of the collection period, all collected feces were separately thawed, pooled, homogenized and subsampled within pig, diet, and period. Fecal sub-samples were obtained after being dried for $72 \mathrm{~h}$ in a $65^{\circ} \mathrm{C}$ drying oven (Tofflon Freezing Drying Systems, Shanghai, China) and ground through a 1-mm screen. During the collection period, orts and feed spillage were collected twice daily, then dried, weighed and recorded.

Table 2. Ingredient composition of experimental diets (as-fed basis)

\begin{tabular}{|c|c|c|c|c|c|c|}
\hline Ingredient (\%) & Corn & SBM & CM & Corn-SBM & Corn-CM & Corn-SBM-CN \\
\hline Corn & 98.45 & - & - & 68.60 & 68.40 & 68.45 \\
\hline SBM & - & 30.00 & - & 30.00 & - & 15.00 \\
\hline CM & - & - & 30.00 & - & 30.00 & 15.00 \\
\hline Cornstarch & - & 59.00 & 48.75 & - & - & - \\
\hline Sucrose & - & 10.00 & 20.00 & - & - & - \\
\hline Limestone & 0.75 & 0.20 & 0.45 & 0.60 & 0.80 & 0.75 \\
\hline Salt & 0.30 & 0.30 & 0.30 & 0.30 & 0.30 & 0.30 \\
\hline Vitamin-mineral premix ${ }^{1)}$ & 0.50 & 0.50 & 0.50 & 0.50 & 0.50 & 0.50 \\
\hline Total & 100.00 & 100.00 & 100.00 & 100.00 & 100.00 & 100.00 \\
\hline
\end{tabular}

SBM, soybean meal; CM, canola meal.

1) Provided the following quantities of vitamins and minerals per $\mathrm{kg}$ of complete diet: $\mathrm{Mn}, 50 \mathrm{mg}(\mathrm{MnO}) ; \mathrm{Fe}_{1}, 125 \mathrm{mg}\left(\mathrm{FeSO}_{4} \cdot \mathrm{H}_{2} \mathrm{O}\right) ; \mathrm{Zn}, 125 \mathrm{mg}(\mathrm{ZnO}) ; \mathrm{Cu}, 150 \mathrm{mg}\left(\mathrm{CuSO} \cdot 5 \mathrm{H}_{2} \mathrm{O}\right)$; I, $50 \mathrm{mg}\left(\mathrm{Cal}_{2}\right) ; \mathrm{Se}, 0.30 \mathrm{mg}\left(\mathrm{Na}_{2} \mathrm{SeO}_{3}\right)$, retinyl acetate, 4,500 IU; cholecalciferol, 1,350 IU; DL- $\alpha$-tocopheryl acetate, $13.5 \mathrm{mg}$; menadione sodium bisulfite complex, $2.7 \mathrm{mg}$; niacin, $18 \mathrm{mg}$; vitamin $\mathrm{B}_{12}, 27.6 \mu \mathrm{g}$; thiamine, $0.6 \mathrm{mg}$; pyridoxine, $0.9 \mathrm{mg}$; riboflavin, $1.8 \mathrm{mg}$; D-calcium-pantothenate, $10.8 \mathrm{mg}$; nicotinic acid, $30.3 \mathrm{mg}$; choline chloride, 210 $\mathrm{mg}$. 


\section{Chemical analysis}

Corn, SBM, CM, and all diet samples were analyzed in duplicate for gross energy (GE) with Automatic Isoperibol Oxygen Bomb Calorimeter (Model 6300; Parr Instruments, Moline, IL, USA), dry matter (DM, method 927.05) [16], ash (method 942.05) [16], CP (method 990.03) [16], acid detergent fiber (ADF), and neutral detergent fiber (NDF) (Ankom Technology method 12 and 13, respectively) with Ankom 2000 Fiber Analyzer (Ankom Technology, Macedon, NY, USA), calcium (Ca, method 968.08) [16] with an Atomic Absorption Spectrometer (Z-2000, Hitachi, Tokyo, Japan), P (method 931.01) [16] with a UV-visible Spectrophotometer after wet-digestion (U-1000, Hitachi, Japan), and phytate [17], respectively (Tables 1,3 ). The concentration of phytate-bound $\mathrm{P}$ in each ingredient was calculated as $28.2 \%$ of phytate [18], and nonphytate-bound $\mathrm{P}$ was calculated as the difference between the concentration of total $\mathrm{P}$ and phytatebound P. Fecal samples were also analyzed in duplicate for concentrations of $\mathrm{DM}, \mathrm{Ca}$, and $\mathrm{P}$ as explained for the ingredients and diets.

\section{Calculations and statistical analysis}

Values for ATTD and STTD of P were calculated in each diet according to the following equations [3]:

$$
\begin{aligned}
& \text { ATTD of } \mathrm{P}(\%)=\left[\left(\mathrm{P}_{\mathrm{i}}-\mathrm{P}_{\mathrm{f}}\right) / \mathrm{P}_{\mathrm{i}}\right] \times 100 \\
& \text { STTD of } \mathrm{P}(\%)=\left[\mathrm{P}_{\mathrm{i}}-\left(\mathrm{P}_{\mathrm{f}}-\text { Basal EPL }\right) / \mathrm{P}_{\mathrm{i}}\right] \times 100
\end{aligned}
$$

Where $\mathrm{P}_{\mathrm{i}}$ is the total P intake $(\mathrm{g})$ in the collection period, $\mathrm{P}_{\mathrm{f}}$ is the total fecal $\mathrm{P}$ output $(\mathrm{g})$ originating from the feed that are provided in the collection period, and basel EPL is the total tract basal endogenous losses of $\mathrm{P}$. The daily basal EPL $(\mathrm{mg} / \mathrm{d})$ for each diet was calculated by multiplying the EPL (190 mg/kg DMI according to NRC [4]) by the daily DMI of each diet. Because corn, SBM or CM is the only P-contributing ingredient in each diet, these values also represent the
ATTD and STTD P values for each ingredient.

The additivity of the ATTD or STTD of P in corn, SBM, and $\mathrm{CM}$ was analyzed as a completely randomized design using the following model:

$$
\mathrm{Y}_{i j}=\mu+\alpha_{i}+\varepsilon_{i j}
$$

Where $\mu$ is the overall mean, $\alpha_{i}$ is the effect of $i$ th diet, and $\varepsilon_{i j}$ is the error term. Normality was tested and outliers were identified using the Proc UNIVARIATE procedure in SAS (SAS Institute Inc., Cary, NC, USA). Data were analyzed using the Proc Mixed procedure in SAS. Means were separated using the least significant difference (LSD) test, and an a level of 0.05 was used to assess significant differences among means. Pig was the experimental unit for all calculations and statistical significance and tendencies were considered at $\mathrm{p}<0.05$ and $0.05 \leq \mathrm{p}<0.10$, respectively.

To test if the difference between ATTD $_{\mathrm{CM}}$ (calculated ATTD in mixture of corn-SBM, corn-CM, or corn-SBM-CM) and ATTD $_{\text {DM }}$ (determined ATTD in mixture of corn-SBM, corn$\mathrm{CM}$, or corn-SBM-CM) had reached a statistically significant level, a 2-tailed $t$-test was used with the null hypothesis being $\mathrm{H}_{0}$ : $\mathrm{ATTD}_{\mathrm{DM}}=\mathrm{ATTD}_{\mathrm{CM}}$ vs alternative hypothesis $\mathrm{H}_{\mathrm{a}}$ : $\mathrm{ATTD}_{\mathrm{DM}} \neq \mathrm{ATTD}_{\mathrm{CM}}$. A t statistic was performed:

$$
\mathrm{t}=(\bar{\chi}-\mu) / \mathrm{SE}
$$

In which $\operatorname{ATTD}_{\mathrm{DM}}$ was taken as the sample mean $(\bar{x})$ and $\operatorname{ATTD}_{\mathrm{CM}}$ as the population mean $(\mu)$. The $\mathrm{ATTD}_{\mathrm{CM}}$ was calculated as sum of the products between the ATTD of each single ingredient and the contribution of this ingredient in the whole diet.

The test of difference between $\mathrm{STTD}_{\mathrm{CM}}$ and $\mathrm{STTD}_{\mathrm{DM}}$ was

\begin{tabular}{|c|c|c|c|c|c|c|}
\hline Item & Corn & SBM & $\mathrm{CM}$ & Corn-SBM & Corn-CM & Corn-SBM-CM \\
\hline GE (kcal/kg) & 3,797 & 3,718 & 3,827 & 3,890 & 3,880 & 3,949 \\
\hline DM & 88.39 & 89.51 & 91.17 & 88.44 & 88.68 & 88.53 \\
\hline $\mathrm{CP}(\mathrm{N} \times 6.25)$ & 8.55 & 14.43 & 11.29 & 19.95 & 16.86 & 18.40 \\
\hline NDF & 9.21 & 3.81 & 7.04 & 7.06 & 11.52 & 13.57 \\
\hline ADF & 2.56 & 2.09 & 5.77 & 4.43 & 7.69 & 10.56 \\
\hline Ash & 2.59 & 2.73 & 3.04 & 3.93 & 4.35 & 4.17 \\
\hline $\mathrm{Ca}$ & 0.32 & 0.21 & 0.46 & 0.33 & 0.37 & 0.40 \\
\hline$P$ & 0.36 & 0.26 & 0.38 & 0.44 & 0.58 & 0.53 \\
\hline STTD P & 0.07 & 0.09 & 0.10 & 0.19 & 0.20 & 0.19 \\
\hline
\end{tabular}
the same procedure as that for $\mathrm{ATTD}_{\mathrm{CM}}$ and $\mathrm{ATTD}_{\mathrm{DM}}$.

\section{RESULTS}

Table 3. Analyzed chemical composition of experimental diets (\%, unless otherwise indicated; as-fed basis)

SBM, soybean meal; CM, canola meal; GE, gross energy; DM, dry matter; CP, crude protein; NDF, neutral detergent fiber; ADF, acid detergent fiber; STTD, standardized total tract digestible.

Values for STTD P were calculated from NRC [4]. 
Table 4. Phosphorus (P) intake in feed and output in feces, and apparent and standardized total tract digestibility (ATTD and STTD) of P in diets containing corn, soybean meal (SBM) or canola meal $(\mathrm{CM})^{1)}$

\begin{tabular}{|c|c|c|c|c|c|c|c|c|}
\hline \multirow{2}{*}{ Item } & \multicolumn{6}{|c|}{ Diets } & \multirow{2}{*}{ SEM } & \multirow{2}{*}{ p-value } \\
\hline & Corn & SBM & CM & Corn-SBM & Corn-CM & Corn-SBM-CM & & \\
\hline Feed intake (g DM/d) & 752 & 764 & 772 & 754 & 755 & 752 & 10.22 & 0.993 \\
\hline P intake (g/d) & $3.08^{d}$ & $2.26^{\mathrm{e}}$ & $3.24^{d}$ & $3.84^{c}$ & $4.97^{\mathrm{a}}$ & $4.50^{b}$ & 0.16 & $<0.001$ \\
\hline $\mathrm{P}$ in feces $(\%)$ & $2.25^{b}$ & $2.34^{b}$ & $2.72^{\mathrm{a}}$ & $2.36^{\mathrm{b}}$ & $2.46^{\mathrm{b}}$ & $2.43^{b}$ & 0.04 & 0.006 \\
\hline P output (g/d) & $2.05^{c}$ & $1.13^{d}$ & $2.10^{c}$ & $2.21^{\mathrm{c}}$ & $3.18^{\mathrm{a}}$ & $2.66^{b}$ & 0.11 & $<0.001$ \\
\hline P absorbed (g/d) & $1.03^{b}$ & $1.13^{b}$ & $1.14^{\mathrm{b}}$ & $1.62^{\mathrm{a}}$ & $1.80^{\mathrm{a}}$ & $1.85^{\mathrm{a}}$ & 0.07 & $<0.001$ \\
\hline ATTD of $P(\%)$ & $33.12^{c}$ & $50.19^{a}$ & $34.93^{b c}$ & $42.07^{b}$ & $36.0^{9 b c}$ & $40.97^{b}$ & 1.02 & $<0.001$ \\
\hline Basal EPL ${ }^{2)}(\mathrm{mg} / \mathrm{d})$ & 143 & 145 & 147 & 143 & 143 & 143 & 1.94 & 0.993 \\
\hline STTD of $P(\%)$ & $37.76^{c}$ & $56.62^{\mathrm{a}}$ & $39.45^{b c}$ & $45.81^{b}$ & $38.97^{b c}$ & $44.15^{b c}$ & 1.02 & $<0.001$ \\
\hline
\end{tabular}

SEM, standard error of the mean; DM, dry matter; EPL, endogenous P losses; DMI, dry matter intake.

1) Data are means of 6 observations per treatment.

2) The total tract basal endogenous losses of P was assumed to be $190 \mathrm{mg} / \mathrm{kg}$ DMI [4]. The daily basal EPL (mg/d) for each diet was calculated by multiplying the EPL (mg/kg DMI) by the daily DMI of each diet.

${ }^{a \cdot e}$ Means within a row with no common letter are different $(p<0.05)$.

\section{Digestibility of $\mathbf{P}$ in diets}

No differences were observed in average daily feed intake (Table 4). However, pigs fed corn-CM diet had greater $(\mathrm{p}<0.05)$ daily $\mathrm{P}$ intake than pigs fed the other diets, whereas pigs fed SBM diet had less $(\mathrm{p}<0.05)$ daily $\mathrm{P}$ intake than the others. Phosphorus in feces $(\%)$ in $\mathrm{CM}$ diet was greater $(\mathrm{p}<0.05)$ than that in the other diets. Daily $\mathrm{P}$ output in corn-CM diet was greater $(\mathrm{p}<0.05)$ than that in the other diets, whereas daily $\mathrm{P}$ output in SBM diet was less $(\mathrm{p}<0.05)$ than that in the other diets. Pigs fed corn-SBM, corn-CM, and corn-SBM-CM diets had greater $(\mathrm{p}<0.05)$ daily absorbed $\mathrm{P}$ than pigs fed corn, SBM, and CM diets. The ATTD and STTD of P in SBM diet was greater $(\mathrm{p}<0.05)$ than that in the other diets, whereas the ATTD of $P$ in corn diet was less $(p<0.05)$ than that in cornSBM and corn-SBM-CM diets, and the STTD of $\mathrm{P}$ in corn diet was less $(\mathrm{p}<0.05)$ than that in corn-SBM diet. However, no differences were observed in daily basal EPL among treatments.

\section{Additivity of values for ATTD and STTD of P in corn,} $\mathrm{SBM}$, and $\mathrm{CM}$ in diets

Values for ATTD of $\mathrm{P}$ in corn, $\mathrm{SBM}$, and $\mathrm{CM}$ in growing pigs were $33.12 \%, 50.19 \%$, and $34.93 \%$, respectively. Values for STTD of $\mathrm{P}$ in corn, SBM, and CM in growing pigs were $37.76 \%, 56.62 \%$, and $39.45 \%$, respectively. We could not reject the $\mathrm{H}_{0}$ hypothesis that $\mathrm{ATTD}_{\mathrm{DM}}=\mathrm{ATTD}_{\mathrm{CM}}$ for corn-SBM diet and corn-CM diet, so the determined ATTD of P in the mixture of corn and SBM, and corn and CM is not different from the calculated ATTD (Table 5). However, the determined ATTD of $\mathrm{P}$ in the mixture of corn, SBM, and CM was greater $(p<0.05)$ than the calculated ATTD. We could not reject the $\mathrm{H}_{0}$ hypothesis that $\mathrm{STTD}_{\mathrm{DM}}=\mathrm{STTD}_{\mathrm{CM}}$ for corn-SBM, corn$\mathrm{CM}$, and corn-SBM-CM diets, so the determined STTD of $\mathrm{P}$ in the mixture of corn and SBM, corn and $\mathrm{CM}$, and corn, $\mathrm{SBM}$, and CM is not different from the calculated STTD.

\section{DISCUSSION}

\section{Composition of ingredients}

Analyzed GE, DM, NDF, ADF, and ash in corn, SBM, and CM in the present experiment are in agreement with the values reported by NRC [4]. Analyzed CP in SBM and CM concurs with NRC [4], whereas in corn is less than NRC [4]. Concentration of $\mathrm{Ca}$ in corn concurs with previous data $[11,13]$, but the concentration of total $\mathrm{P}$ and phytate were greater in corn compared with data reported previously $[4,19]$. Most of $\mathrm{P}$ in cereals is bound to phytate, which results in low digestibility of $\mathrm{P}$ for pigs because of lack of endogenous phytase [20]. The binding to phytate also results in a relatively large output of

Table 5. Calculated and determined values for apparent and standardized total tract digestibility (ATTD and STTD) for phosphorus (P) in a corn-soybean meal (SBM), corncanola meal (CM), or corn-SBM-CM based diet ${ }^{1)}$

\begin{tabular}{|c|c|c|c|c|c|c|c|c|}
\hline \multirow{2}{*}{ Item } & \multicolumn{2}{|c|}{ ATTD of $P(\%)$} & \multirow{2}{*}{ SEM } & \multirow{2}{*}{$p$-value } & \multicolumn{2}{|c|}{ STTD of $P(\%)$} & \multirow{2}{*}{ SEM } & \multirow{2}{*}{ p-value } \\
\hline & Calculated values & Determined values & & & Calculated values & Determined values & & \\
\hline Corn-SBM & 42.80 & 40.93 & 2.96 & 0.815 & 48.98 & 44.66 & 2.96 & 0.333 \\
\hline Corn-CM & 33.15 & 36.09 & 1.71 & 0.146 & 38.00 & 38.97 & 1.71 & 0.592 \\
\hline Corn-SBM-CM & 37.00 & 40.97 & 1.06 & 0.014 & 42.87 & 44.14 & 1.06 & 0.480 \\
\hline
\end{tabular}

1) Data are means of 6 observations per treatment. 
$\mathrm{P}$ in feces and reduces the bioavailability of other minerals such as $\mathrm{Ca}, \mathrm{Mn}, \mathrm{Zn}$, and $\mathrm{Fe}$ [20]. Concentrations of total $\mathrm{P}$ and phytate in SBM are within the range reported previously $[4,14]$, but the concentration of $\mathrm{Ca}$ is greater than previously reported value $[14,21]$. The concentrations of $\mathrm{Ca}$, total $\mathrm{P}$, and phytate in $\mathrm{CM}$ are in agreement with previous publications $[4,12,22]$.

\section{Differences in digestibility of $\mathrm{P}$ among corn, SBM, and CM}

The difference of $\mathrm{P}$ intake and output among diets can be explained by different phytate-bound $\mathrm{P}$ concentrations in corn, SBM, and CM used in this experiment. Apparent total tract digestibility of $\mathrm{P}$ has been determined in several feed ingredients [13], but basal EPL is not included in the calculation for ATTD. Basal EPL can be determined using a P-free diet [7]. If ATTD is corrected based on basal EPL, values for STTD of $\mathrm{P}$ are calculated [4]. At present, standardized total tract digestibility has been widely used to evaluate AP in feed ingredients for pigs $[4,11,13]$. The ATTD and STTD of P in corn fed to pigs obtained in this experiment are within the range reported by previous studies $[3,7,11,13,19]$. The ATTD and STTD of P in SBM are also in accordance with some previous reports $[10,14,21,23]$, but are greater than values reported by Almaguer et al [6]. The difference may be explained by the different processes used for producing SBM in feed industry, during which the amount of hulls removed prior to oil extraction varies. Because there are about $61 \%$ hulls in soybean, the seeds may either be decorticated (dehulled) or un-decorticated [24].

Our result showed that the ATTD and STTD of P in corn and $\mathrm{CM}$ are less than those in SBM. The differences in $\mathrm{P}$ digestibility among corn, SBM, and CM can be explained by differences in the concentrations of nonphytate-bound P. In the current study, the concentration of nonphytate-bound $\mathrm{P}$ in corn and CM is less than that in SBM. Some previous studies on other oilseed meals reported a strong negative relationship between phytate-bound P and the ATTD or STTD of P, thus indicated that phytate-bound $\mathrm{P}$ concentration can be used as a predictor for STTD of $\mathrm{P}$ in these ingredients $[5,6,25]$. The results in our study confirmed this principle in SBM and CM, with $\mathrm{CM}$ having more phytate-bound $\mathrm{P}$ and lower $\mathrm{P}$ digestibility. Although the digestibility of P in SBM is greater than that in $\mathrm{CM}$, the total $\mathrm{P}$ concentration in $\mathrm{CM}$ is relatively high, thus the digestible $\mathrm{P}$ in $\mathrm{CM}$ is still greater than that in SBM. This result indicated that in addition to providing protein, $\mathrm{CM}$ can also be an optional $\mathrm{P}$ source among plant feed ingredients in swine diets.

Additivity of values for ATTD and STTD of P in corn, SBM, and CM in diets

The additivity of values for $\mathrm{P}$ digestibility is a crucial factor in the formulation of swine diets. Usually, it is assumed that the supply of nutrients in a mixed diet is equal to the sum of its constitutive components on the basis of the digestibility values determined from individual ingredient [26]. The additivity in the context of $\mathrm{P}$, as showed for additivity of AA [27], should be conceptualized as that the total digestible $\mathrm{P}$ in diet equals to the sum of digestible $\mathrm{P}$ in individual ingredient contributing $\mathrm{P}$ to the mixed diet. Fang et al [26] demonstrated that true total tract digestibility (TTTD) of P values are additive in feed ingredients containing low levels of phytatebound P and anti-nutritional factors, whereas the ATTD of $P$ values are not always additive in individual feed ingredient for pigs. However, there could be great variation in ATTD of $\mathrm{P}$ based on the substitution method used in that study, especially when the inclusion rate of the test ingredient was low in the experimental diet [28]. Our results showed that there were no differences between determined and calculated STTD of $\mathrm{P}$ values in corn-SBM, corn-CM, or corn-SBM-CM, suggesting that STTD of $\mathrm{P}$ in corn, SBM, and CM for 21-kg pigs are additive. This result agrees with Zhai and Adeola [29] who reported that TTTD of P in corn and SBM for 15-kg pigs are additive in corn-SBM diet.

In contrast, in this experiment, the calculated ATTD of P values in corn-SBM-CM diet was less than the determined values, which may be due to the existence of EPL in pigs. This observation clearly showed that values for ATTD of P in corn, SBM, and CM are not additive in mixed diet, which agrees with previous publications $[4,29]$. It also indicates that ATTD of $\mathrm{P}$ is not influenced by dietary $\mathrm{P}$ level and does not affect the determination of TTTD of $\mathrm{P}$ for pigs [30]. The additivity of ATTD of $\mathrm{P}$ values for pigs may depend on the property of component ingredients of the experimental diets, such as anti-nutritional factors [26,31]. As for scenarios where the component ingredients in diets are different in the content of inherent phytase, as in the case of corn and rye in the same diet, the additivity may not be so straightforward, which needs further investigation [29].

In this study, due to the inaccessible of the P-free diet, the basal EPL of growing pigs was calculated based on NRC [4] rather than determined through animal trial. The basal EPL should be relatively stable, but it can also be slightly affected by factors such as animal age, composition of the P-free diet, fecal collection time and method based upon studies in other animals [32]. Similar studies on growing pigs is still lacking by now. Thus we assumed the experimental error brought by EPL measurement would not affect the results of the additivity, but more studies are needed to ensure the accuracy of the evaluation. Corn, SBM, and CM are the most common ingredients in swine feed industry, and our results suggest that the STTD values of $\mathrm{P}$ are reliable in formulating diets based on corn, SBM, and CM for pigs. Further studies are also needed to evaluate additivity of $\mathrm{P}$ in more feedstuffs fed to pigs. 


\section{CONCLUSION}

In conclusion, the ATTD of P in corn, SBM, and CM fed to growing pigs are $33.12 \%, 50.19 \%$, and $34.93 \%$, respectively, and the respective STTD of P in corn, SBM, and CM are $37.76 \%, 56.62 \%$, and $39.45 \%$. The expected STTD values in the mixture of corn, SBM, and CM are not different from the determined digestibility values, indicating the additivity of STTD of $\mathrm{P}$ in corn, SBM, and CM for pigs.

\section{CONFLICT OF INTEREST}

We certify that there is no conflict of interest with any financial organization regarding the material discussed in the manuscript.

\section{ACKNOWLEDGMENTS}

The authors wish to acknowledge the financial support received from the " 863 " National High-tech R\&D Program (2013AA10230602), National Key Technology R\&D Program in the 11th Five Year Plan of China (2006BAD12B01) and Special Public Sector Fund in Agriculture (200903006).

\section{REFERENCES}

1. Emiola A, Akinremi O, Slominski B, Nyachoti CM. Nutrient utilization and manure $\mathrm{P}$ excretion in growing pigs fed cornbarley-soybean based diets supplemented with microbial phytase. Anim Sci J 2009;80:19-26.

2. Woyengo TA, Ige DV, Akinremi OO, Nyachoti CM. Performance and nutrient digestibility in growing pigs fed wheat dried distillers' grain with solubles-containing diets supplemented with phytase and multi-carbohydrase. Anim Sci J 2016; 87:570-7.

3. Almeida FN, Stein HH. Performance and phosphorus balance of pigs fed diets formulated on the basis of values for standardized total tract digestibility of phosphorus. J Anim Sci 2010;88:2968-77.

4. NRC. Nutrient requirements of swine. 11th rev. ed. Washington, DC, USA: National Academy Press; 2012.

5. Rodríguez DA, Sulabo RC, González-Vega JC, Stein HH. Energy concentration and phosphorus digestibility in canola, cottonseed, and sunflower products fed to growing pigs. Can J Anim Sci 2013;93:493-503.

6. Almaguer BL, Sulabo RC, Liu Y, Stein HH. Standardized total tract digestibility of phosphorus in copra meal, palm kernel expellers, palm kernel meal, and soybean meal fed to growing pigs. J Anim Sci 2014;92:2473-80.

7. Petersen GI, Stein HH. Novel procedure for estimating endogenous losses and measurement of apparent and true digestibility of phosphorus by growing pigs. J Anim Sci 2006;84:
2126-32.

8. González-Vega JC, Stein HH. Amino acid digestibility in canola, cottonseed and sunflower products fed to finishing pigs. J Anim Sci 2012;90:4391-400.

9. Cotten B, Ragland D, Thomson JE, Adeola O. Amino acid digestibility of plant protein feed ingredients for growing pigs. J Anim Sci 2016;94:1073-82.

10. Rojas OJ, Stein HH. Digestibility of phosphorus by growing pigs of fermented and conventional soybean meal without and with microbial phytase. J Anim Sci 2012;90:1506-12.

11. Rojas OJ, Liu Y, Stein HH. Phosphorus digestibility and concentration of digestible and metabolizable energy in corn, corn coproducts, and bakery meal fed to growing pigs. J Anim Sci 2013;91:5326-35.

12. Maison T, Liu Y, Stein HH. Apparent and standardized total tract digestibility by growing pigs of phosphorus in canola meal from North America and 00-rapeseed meal and 00-rapeseed expellers from Europe without and with microbial phytase. J Anim Sci 2015;93:3494-502.

13. She Y, Su YB, Liu L, et al. Effects of microbial phytase on coefficient of standardized total tract digestibility of phosphorus in growing pigs fed corn and corn co-products, wheat and wheat co-products and oilseed meals. Anim Feed Sci Technol 2015;208:132-44.

14.Sotak-Peper KM, González-Vega JC, Stein HH. Effects of production area and microbial phytase on the apparent and standardized total tract digestibility of phosphorus in soybean meal fed to growing pigs. J Anim Sci 2016;94:2397-402.

15.Song GL, Li DF, Piao XS, Chi F, Yang WJ. Apparent ileal digestibility of amino acids and the digestible and metabolizable energy content of high-oil corn varieties and its effects on growth performance of pigs. Arch Anim Nutr 2003;57:297306.

16. AOAC International. Official Methods of Analysis. 18th ed. Hortwitz W, Latimer Jr., GW, editors. Gaithersburg, MD, USA: AOAC International; 2007.

17. Ellis R, Morris ER, Philpot C. Quantitative determination of phytate in the presence of high inorganic phosphate. Anal Biochem 1977;77:536-9.

18. Sauvant D, Perez JM, Tran G. Tables of composition and nutritional value of feed materials: pig, poultry, sheep, goats, rabbits, horses, and fish. 2nd ed. Wageningen, the Netherlands: Wageningen Academic Publishers; 2004.

19. Almeida FN, Stein HH. Effects of graded levels of microbial phytase on the standardized total tract digestibility of phosphorus in corn and corn coproducts fed to pigs. J Anim Sci 2012;90:1262-9.

20. Casas GA, Stein HH. Effects of microbial phytase on the apparent and standardized total tract digestibility of phosphorus in rice coproducts fed to growing pigs. J Anim Sci 2015;93: 3441-8.

21. Akinmusire AS, Adeola O. True digestibility of phosphorus 
in canola and soybean meals for growing pigs: Influence of microbial phytase. J Anim Sci 2009;87:977-83.

22. Adhikari PA, Heo JM, Nyachoti CM. High dose of phytase on apparent and standardized total tract digestibility of phosphorus and apparent total tract digestibility of calcium in canola meals from Brassica napus black and Brassica juncea yellow fed to growing pigs. Can J Anim Sci 2016;96:121-7.

23. Oliveira MS, Stein HH. Digestibility of energy, amino acids, and phosphorus in a novel source of soy protein concentrate and in soybean meal fed to growing pigs. J Anim Sci 2016;94: 3343-52.

24. Von NT, St. Louis DG, Orr AL, Rude BJ. Supplementing maize or soybean hulls to cattle fed rice straw: intake, apparent digestion, in situ disappearance and ruminal dynamics. AsianAustralas J Anim Sci 2008;21:807-17.

25. Matsui T. Relationship between mineral availabilities and dietary phytate in animals. Anim Sci J 2002;73:21-8.

26. Fang RJ, Li TJ, Yin FG, et al. The additivity of true or apparent phosphorus digestibility values in some feed ingredients for growing pigs. Asian-Australas J Anim Sci 2007;20:1092-9.

27.Stein HH, Pedersen C, Wirt AR, Bohlke RA. Additivity of values for apparent and standardized ileal digestibility of amino acids in mixed diets fed to growing pigs. J Anim Sci 2005;83: 2387-95.

28. Düngelhoef M, Rodehutscord M, Spiekers H, Pfeffer E. Effects of supplemental microbial phytase on availability of phosphorus contained in maize, wheat and triticale to pigs. Anim Feed Sci Technol 1994;49:1-10.

29. Zhai H, Adeola O. True total-tract digestibility of phosphorus in monocalcium phosphate for 15-kg pigs. J Anim Sci 2013; 90:98-100.

30.Liu JB, Cao SC, Chen L, Zhang HF. Effect of dietary phosphorus level on the determination of standardized and true total tract digestibility of phosphorus for growing pigs. Anim Feed Sci Technol 2016;215:117-23.

31.Fan MZ, Sauer WC. Additivity of apparent ileal and fecal phosphorus digestibility values measured in single feed ingredients for growing-finishing pigs. Can J Anim Sci 2002;82: 183-91.

32. She Y, Li DF, Zhang S. Methodological aspects of determining phosphorus digestibility in swine: A review. Anim Nutr J 2017; 2:97-102. 